\title{
ELASTIC-PLASTIC TRANSITION ON ROTATING SPHERICAL SHELLS IN DEPENDENCE OF COMPRESSIBILITY
}

\author{
Pankaj Thakur ${ }^{1 *}$, Gaurav Verma ${ }^{2}$, D.S. Pathania ${ }^{3}$, Satya Bir Singh ${ }^{4}$ \\ ${ }^{1}$ Department of Mathematics, ICFAI University Baddi, Solan, Himachal Pradesh 174103, \\ India \\ ${ }^{2}$ Department of Applied Science, I.K. Gujral, Punjab Technical University Jalandhar, \\ Ibban, Kapurthala144603, India \\ ${ }^{3}$ Department of Mathematics, Guru Nanak Dev Engineering College Ludhiana, \\ Punjab 141006, India \\ ${ }^{4}$ Department of Mathematics, Punjabi University Patiala, Punjab 147002, India \\ *Corresponding author; E-mail:dr_pankajthakur@yahoo.com
}

(Received April22, 2016; Accepted September 2, 2016)

\begin{abstract}
The purpose of this paper is to establish the mathematical model on the elastic-plastic transitions occurring in the rotating spherical shells based on compressibility of materials. The paper investigates the elastic-plastic stresses and angular speed required to start yielding in rotating shells for compressible and incompressible materials. The paper is based on the non-linear transition theory of elastic-plastic shells given by B.R. Seth. The elastic-plastic transition obtained is treated as an asymptotic phenomenon at critical points \& the solution obtained at these points generates stresses. The solution obtained does not require the use of semi-empirical yield condition like Tresca or Von Mises or other certain laws. Results are obtained numerically and depicted graphically. It has been observed that Rotating shells made of the incompressible material are on the safer side of the design as compared to rotating shells made of compressible material. The effect of density variation has been discussed numerically on the stresses. With the effect of density variation parameter, rotating spherical shells start yielding at the internal surface with the lower values of the angular speed for incompressible/compressible materials.
\end{abstract}

Keywords: Shells, elastic-plastic, yielding, stress, strain, speed, compressibility

\section{INTRODUCTION}

Rotating shell structures have many engineering applications like aviation, rocketry, missiles, electric motors and locomotive engines. Engineers have found its increasing application in aerospace, chemical, civil and mechanical industries such as in high-speed centrifugal separators, gas turbines for high-power aircraft engines, spinning satellite structures, certain rotor systems and rotating magnetic shields (SHAMBHARKAR, 2008). To increase the strength of shells or shafts, it is, therefore, very important for engineers to study the behavior of transition of rotating shells. A shell is a curved surface, in which the thickness is much smaller than the remaining dimensions. The geometrical properties of shells, i.e. single or double curvature give rise to a tremendous advantage of these light-weight structures 
(WOELKe, 2005). Analysis and design of these structures are, therefore, continuously of interest to the scientific and engineering community. The accurate and conservative assessments of the maximum load carried by the structure, as well as the equilibrium path in both elastic and plastic range are of paramount importance. Solutions for thin spherical shells can be found in most of the standard elasticity and plasticity textbooks (TIMOSHENKO and GOODIER, 1970; CHAKRABARTY, 1987). Elastic behavior of shells has been very closely investigated, mostly by means of the finite element method. Many authors like R. EBERLEIN, Wriggers, CIVALEK, GÜRSES have done elastic-plastic calculations in shells by using the various theoretical and numerical approaches based on finite element method, shear deformation theory, discrete convolution technique (SCHMIDT and WEICHERT, 1989; SIMO et al.,1990; Eberlein and Wriggers, 1999; CivaleK and GÜrSES, 2009). This paper is based on the non-linear transition theory of elastic-plastic shells. Here in this paper, the elasticplastic problem of rotating spherical shells based on the different degree of compressibility has been solved by using the concept of generalized strain measures and transition theory. The distribution of stresses and yielding in an elastic-plastic rotating shell has been calculated by using the concept of generalized strain measures and the generalized Hooke's law at the critical points of the non-linear differential equation defining the equilibrium stage. The transition theory of elastic-plastic of shells do not use the ad-hoc assumptions like incompressibility, yield conditions those of Tresca, Von Mises and creep-strain laws like those of Norton, ODQVIST (1964). This theory has been used to solve various elastic-plastic transition problems (SETH, 1963; HUlSARKAR, 1981; GUPTA and PATHAK, 2000). SETH (1966) has defined the concept of generalized strain measure as

$e_{i i}=\int_{0}^{e_{i i}^{A}}\left[1-2 e_{i i}^{A}\right]^{\frac{n-2}{2}} d e_{i i}^{A}=\frac{1}{n}\left[1-\left(1-2 e_{i i}^{A}\right)^{\frac{n}{2}},(i=1,2,3)\right.$

where $n$ is the measure $e_{i i}^{A}$ is the almansi finite strain components.

The accurate calculation of radial and circumferential stresses is essential for efficient design and long life of mechanical structures. In this paper, elastic-plastic stresses are determined by using the asymptotic solution at critical points and required angular speed to start initial yielding in the shell without using any semi-empirical yield condition and other certain laws. We analyze the non-linear transition problem of thin rotating spherical shell by using the generalized strain measures and Seth's transition theory for different values of the compressibility. The effect of density variation parameter has been discussed numerically and depicted graphically.

\section{MATHEMATICAL MODEL}

Consider aspherical shell of constant thickness with the internal radius $a$ and the external radius $b$. The shell is rotating with angular velocity $\omega$ about an axis perpendicular to its plane and passing through the center of the shell so that the axial stress is zero. The thickness of the shell is constant and is effectively in a state of plane stress. The spherical shell considered in the present study has no stress initially. The inner surface of the spherical shell is assumed to be fixed to a shaft. 


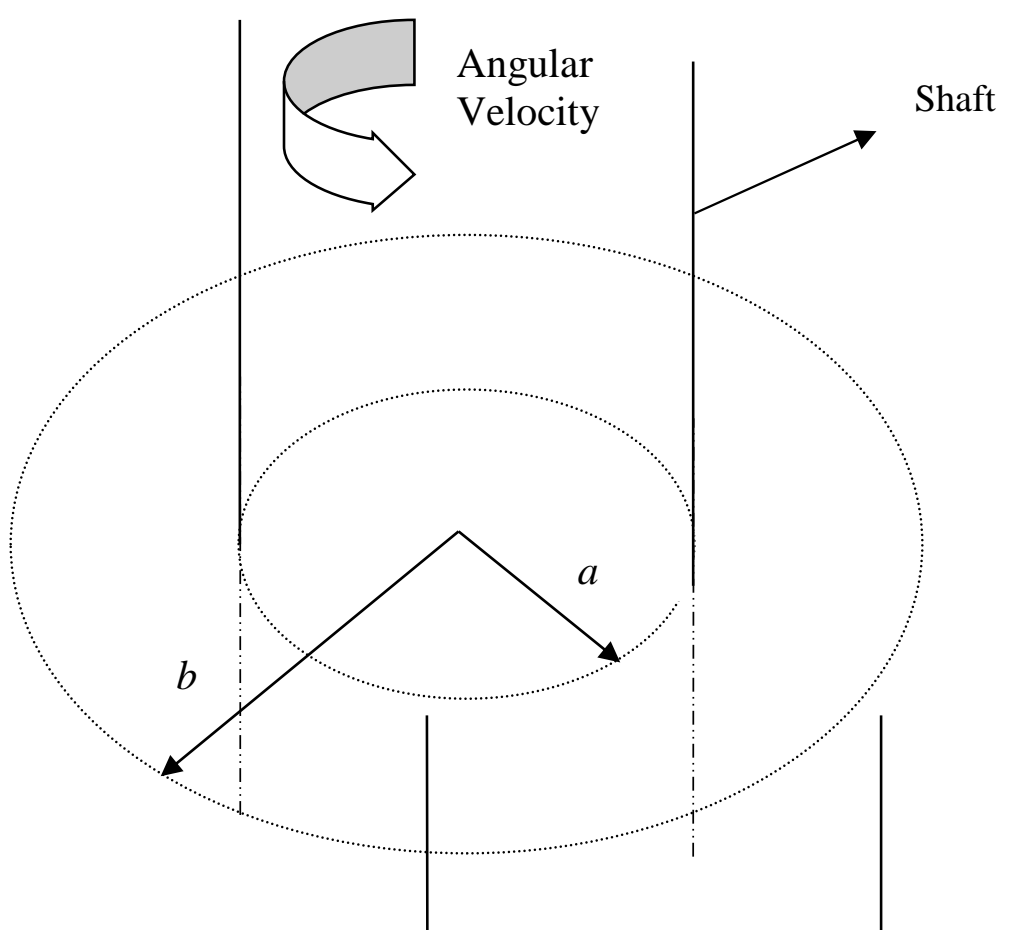

Figure1. Geometry of rotating spherical shell.

\section{Formulation of the problem:}

Due to the symmetry in the elastic properties, the displacement is purely radial. Therefore, we take the displacements in spherical coordinates as $(r, \theta, \phi)$.

$\mathrm{u}=\mathrm{r}(1-\beta), \mathrm{v}=0, \mathrm{w}=0$ where $\beta$ is function of $\mathrm{r}=\sqrt{x^{2}+y^{2}+z^{2}}$

The finite strain components are given by Seth as

$e_{r r}^{A}=\frac{1}{2}\left[1-\left(r \beta^{\prime}+\beta\right)^{2}\right] \quad, e_{\theta \theta}^{A}=e_{\varphi \varphi}^{A}=\frac{1}{2}\left(1-\beta^{2}\right)$

$e_{r \theta}^{A}=e_{\theta \varphi}^{A}=e_{r \varphi}^{A}=0$

where $\beta^{\prime}=\frac{d \beta}{d r}$

By using equation (3) in equation (1), the generalized components of the strain are given as

$e_{r r}=\frac{1}{n}\left[1-\left(r \beta^{\prime}+\beta\right)^{n}\right], e_{\theta \theta}=e_{\varphi \varphi}=\frac{1}{n}\left(1-\beta^{n}\right)$

$e_{r \theta}=e_{\varphi \theta}=e_{\varphi r}=0$

The stress - strain relations for the isotropic material are given by SOKOLNIKOFF (1946). 
$T_{i j}=\lambda \delta_{i j} I_{1}+2 \mu e_{i j}, \quad(i, j=1,2,3)$

where $\lambda$ and $\mu$ are lame's constants and $I_{1}=e_{k k}$ is called first strain invariant. By using equation (4) in equation (5), the corresponding stresses are given as

$T_{r r}=\frac{\lambda+2 \mu}{n}\left[1-\left(r \beta^{\prime}+\beta\right)^{n}\right]+\frac{2 \lambda}{n}\left(1-\beta^{n}\right)$

$T_{\theta \theta}=T_{\varphi \varphi}=\frac{\lambda}{n}\left[1-\left(r \beta^{\prime}+\beta\right)^{n}\right]+\frac{2 \lambda+2 \mu}{n}\left(1-\beta^{n}\right)$

$T_{r \theta}=T_{\theta \varphi}=T_{r \varphi}=0$

The equations of equilibrium are all satisfied for rotating body except

$r \frac{d\left(T_{r r}\right)}{d r}+T_{r r}-T_{\theta \theta}+\rho \omega^{2} r^{2}=0$

We get the non-linear differential equation by using equation (6) in equation (7) as given

$$
\begin{gathered}
n \beta^{n+1} P(1+P)^{n-1} \frac{d P}{d \beta}=\frac{n c \rho \omega^{2} r^{2}}{2 \mu}+\beta^{n}\left[c\left(1-(1+P)^{n}\right)-n P\left\{2(1-c)+(1+P)^{n}\right\}\right] \\
=0
\end{gathered}
$$

where $\mathrm{c}$ denotes the compressibility of material and given as $c=2 \mu / \lambda+2 \mu, \mathrm{r} \beta^{\prime}=\beta \mathrm{P}$

The transition points of $\beta$ from equation (8) are $P \rightarrow 1$ and $P \rightarrow \pm \infty$ where $P \rightarrow \pm \infty$ corresponds to elastic-plastic transitions and $P \rightarrow 1$ corresponds to creep transitions. So, we take into consideration only $P \rightarrow \pm \infty$.

\section{SOLUTION THROUGH THE PRINCIPAL STRESS}

In order to find the plastic stresses, the transition function is defined using the principal stress as taken by SETH (1963), THAKUR $(2010,2011)$, THAKUR et al. $(2015,2016)$ at the transition point $P \rightarrow \pm \infty$. We define the transition function as

$R=\frac{n}{2 \mu} T_{\theta \theta}=\frac{3-2 c}{c}-\frac{\beta^{n}}{c}\left[(1-c)(1+P)^{n}+(2-c)\right]$

Taking the logarithmic differentiation of equation (9) with respect to $r$ and using equation (8).

$$
\begin{aligned}
& \frac{d \log R}{d r} \\
& =-\frac{n P \beta^{n}(2-c)+\beta^{n} c(1-c)\left[1-(1+P)^{n}-2 n P+\frac{n \rho \omega^{2} r^{2}}{2 \mu \beta^{n}}\right]}{r\left[(3-2 c)-\beta^{n}\left[(1-c)(1+P)^{n}+(2-c)\right]\right]}
\end{aligned}
$$

Now by taking the asymptotic value of equation (10) at $P \rightarrow \pm \infty$ and integrating, we have

$R=A_{1} r^{-c}$ 
where $A_{1}$ is a constant of integration, which can be determined by the boundary conditions. The boundary conditions are given as

$T_{r r}=0$ at $\mathrm{r}=\mathrm{a}$ and $T_{r r}=0$ at $\mathrm{r}=\mathrm{b}$

From equation (9) and equation (10), we get

$T_{\theta \theta}=\frac{2 \mu}{n} A_{1} r^{-c}$

Use equation (12) in equation (7) and integrating, we get as

$T_{r r}=\frac{2 \mu}{n(1-c)} A_{1} r^{-c}-\frac{\rho \omega^{2} r^{2}}{3}+\frac{A_{2}}{r}$

where $A_{2}$ is a constant of integration, which can be determined by using boundary conditions. Therefore, the value of the constants $A_{1}$ and $A_{2}$ are given as

$A_{1}=\frac{\rho \omega^{2} n}{6 \mu} \frac{\left(a^{3}-b^{3}\right)(1-c)}{\left(a^{1-c}-b^{1-c}\right)}$

$A_{2}=\frac{\rho \omega^{2}}{3} \frac{\left(a^{c+2}-b^{c+2}\right)}{\left(a^{c-1}-b^{c-1}\right)}$

By using the values of $A_{1}$ and $A_{2}$ in the equations (12) and (13), we have

$T_{\theta \theta}=\frac{\rho \omega^{2}}{3} \frac{\left(a^{3}-b^{3}\right)(1-c)}{\left(a^{1-c}-b^{1-c}\right)} r^{-c}$

$T_{r r}=\frac{\rho \omega^{2}}{3} \frac{\left(a^{3}-b^{3}\right)}{\left(a^{1-c}-b^{1-c}\right)} r^{-c}-\frac{\rho \omega^{2} r^{2}}{3}+\frac{\rho \omega^{2}}{3 r} \frac{\left(a^{c+2}-b^{c+2}\right)}{\left(a^{c-1}-b^{c-1}\right)}$

Initial Yielding: From equation (16), we can observe that $T_{\theta \theta}$ is maximum at $r=a$, that is the internal surface of the shell. Therefore, the yielding of spherical shell will start at the internal surface given as

$\left|T_{\theta \theta}\right|_{\mathrm{r}=\mathrm{a}}=\frac{\rho \omega^{2}}{3} \frac{\left(a^{3}-b^{3}\right)(1-c)}{\left(a^{1-c}-b^{1-c}\right)} a^{-c} \equiv Y($ say $)$

The angular speed required for initial yielding is given as

$\Omega_{i}^{2}=\frac{\rho \omega^{2} b^{2}}{Y}=\frac{3\left(a^{1-c}-b^{1-c}\right)}{\left(a^{3}-b^{3}\right)} b^{2} a^{-c}$

Fully Plastic state: On increasing the speed of rotation, the yielding in the shell will go on an increase and the shell become more and more plastic for some value of the angular speed. To attain fully plastic state, we will make $c \rightarrow 0$ at the external surface $\mathrm{r}=\mathrm{b}$.

$\left|T_{\theta \theta}\right|_{\mathrm{r}=\mathrm{b}}=\frac{\rho \omega^{2}}{3} \frac{\left(a^{3}-b^{3}\right)}{(a-b)} \equiv Y^{*}(\mathrm{say})$

The angular speed required for Fully plastic state is given as 
$\Omega_{f}^{2}=\frac{\rho \omega^{2} b^{2}}{Y^{*}}=3 b^{2} \frac{(a-b)}{\left(a^{3}-b^{3}\right)}$

Further we are introducing the non-dimensional components as

$\mathrm{R}=\mathrm{r} / \mathrm{b}, R_{o}=\mathrm{a} / \mathrm{b}, \sigma_{r}=T_{r r} / \mathrm{Y}, \sigma_{\theta}=T_{\theta \theta} / \mathrm{Y}$

Therefore, the transitional stresses and the angular speed by using the equations (16), (17) and (19) are as follow

$\sigma_{\theta}=\frac{T_{\theta \theta}}{\mathrm{Y}}=\frac{\Omega_{i}^{2}\left(R_{o}{ }^{3}-1\right)(1-c)}{3\left(R_{o}{ }^{1-c}-1\right)} R^{-c}$

$\sigma_{r}=\frac{T_{r r}}{\mathrm{Y}}=\frac{\Omega_{i}^{2}}{3}\left[\frac{\left(R_{o}{ }^{3}-1\right)}{\left(R_{o}{ }^{1-c}-1\right)} R^{-c}-R^{2}+\frac{1}{R} \frac{\left(R_{o}{ }^{c+2}-1\right)}{\left(R_{o}{ }^{c-1}-1\right)}\right]$

$\Omega_{i}^{2}=\frac{3\left(R_{o}{ }^{1-c}-1\right)}{\left(R_{o}^{3}-1\right)(1-c)} R_{o}^{-c}$

Fully Plastic state:

$\sigma_{\theta}=\frac{\Omega_{f}^{2}}{3}\left(R_{o}{ }^{2}+R_{o}+1\right)$

$\sigma_{r}=\frac{\Omega_{f}^{2}}{3}\left[\left(R_{o}{ }^{2}+R_{o}+1\right)-R^{2}-\frac{R_{o}\left(R_{o}+1\right)}{R}\right]$

$\Omega_{f}^{2}=\frac{3\left(R_{o}-1\right)}{\left(R_{o}^{3}-1\right)}$

These results obtained for transitional stresses and the angular speed for rotating spherical shell is same as given by SHARMA and SAHNI (2009).

\section{DENSITY VARIABLE PARAMETER IN SHELL}

Now we discuss the influence of density on the elastic -plastic stresses in an isotropic thin rotating spherical shell. Consider the density of spherical shell varies along the radius in the following form:

$$
\rho=\rho_{0}\left(\frac{\mathrm{r}}{\mathrm{b}}\right)^{-m}
$$

where $\rho_{0}$ is the constant density taken at $\mathrm{r}=\mathrm{b}$ and $\mathrm{m}$ is the density variable parameter in rotating shell.

By introducing the density variable parameter in the equations (7), (12), (13), (14), (15), we get the values of transitional stresses and angular speed required for the initial yielding and for the fully plastic state.

These expressions in the non - dimensional form are given as Initial Yielding: 
$\sigma_{\theta}=\frac{\Omega_{i}^{2}\left(R_{o}^{3-m}-1\right)(1-c)}{(3-m)\left(R_{o}^{1-c}-1\right)} R^{-c}$

$\sigma_{r}=\frac{\Omega_{i}^{2}}{3-m}\left[\frac{\left(R_{o}{ }^{3-m}-1\right)}{\left(R_{o}{ }^{1-c}-1\right)} R^{-c}-R^{2-m}+\frac{1}{R} \frac{\left(R_{o}{ }^{c+2-m}-1\right)}{\left(R_{o}{ }^{c-1}-1\right)}\right]$

$\Omega_{i}^{2}=\frac{(3-m)\left(R_{o}{ }^{1-c}-1\right)}{\left(R_{o}{ }^{3-m}-1\right)(1-c)} R_{o}{ }^{-c}$

Fully Plastic state:

$\sigma_{\theta}=\frac{\Omega_{f}^{2}\left(R_{o}^{3-m}-1\right)}{(3-m)\left(R_{o}-1\right)}$

$\sigma_{r}=\frac{\Omega_{f}^{2}}{3-m}\left[\frac{\left(R_{o}^{3-m}-1\right)}{\left(R_{o}-1\right)}-R^{2-m}+\frac{1}{R} \frac{\left(R_{O}^{2-m}-1\right)}{\left(R_{o}{ }^{-1}-1\right)}\right]$

$\Omega_{f}^{2}=\frac{(3-m)\left(R_{o}-1\right)}{\left(R_{o}^{3-m}-1\right)}$

For numerical calculations of the stresses and angular speed based on the above formulas, the following numerical values are taken as $\mathrm{C}=0,0.25,0.5,0.75$ and $\mathrm{m}=0,1,2$.

Table1. Angular speed required for initial yielding and fully plastic state.

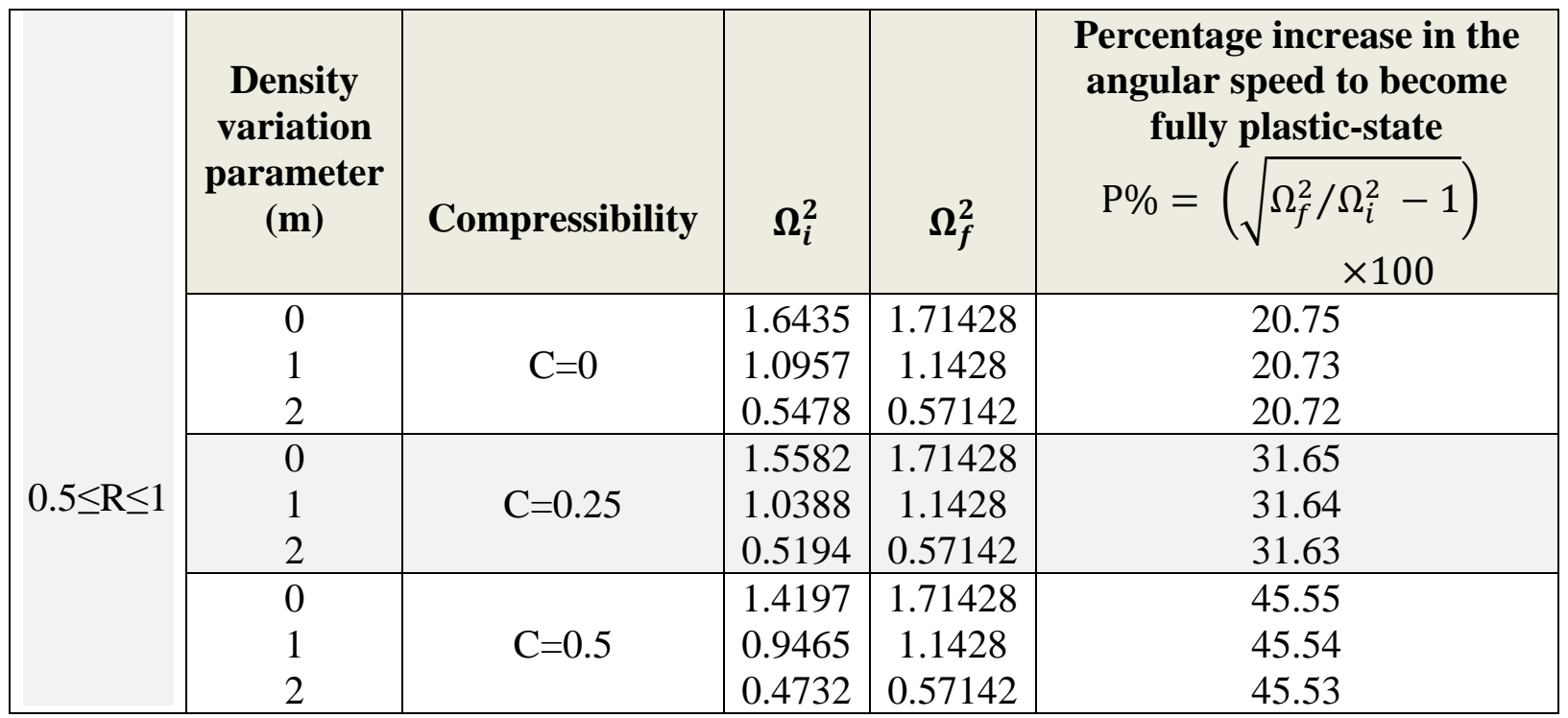

\section{NUMERICAL ILLUSTRATION AND DISCUSSION}

For calculating stresses and angular speed based on the above analysis, the following values have been taken, $v=0.5$ (incompressible material), $v=0.42857,0.333$ and 0.2 (compressible materials). From Table 1, it has been seen that the angular speed required for the initial and fully plastic state is calculated with different compressibility factors. It has been observed that shells made of an incompressible material (like rubber) require higher angular speed as compared to shells made of compressible materials (like plastics, copper) at the inner 
surface (i.e. $r=a$ ). It can also be observed that for compressible material, the higher percentage increase in angular speed is required to attain fully plastic state as compared to rotating spherical shells made of the incompressible material. It is also observed that rotating shells with density variation require lesser angular speed to start yielding as compared to shells without density variation. It means that rotating shell with variable density has a tendency to fracture at the bore of the shell. The curve is produced from fig. 2, between the angular speed required for initial yielding and various radii ratios $R_{0}$ for the different values of compressibility factor $\mathrm{C}$ and density variation parameter $\mathrm{m}$. It has been observed that the compressible materials require lesser angular speed to start yield as compared to incompressible materials in the absence of density variation parameter. Density parameter decreases values of angular speed for incompressible as well as compressible material. Therefore, rotating spherical shells made of the incompressible material is on the safer side of the design as compared to rotating spherical shells made of compressible material. Curves are produced between stresses along the radii ratio $\mathrm{R}=\mathrm{r} / \mathrm{b}$ for compressible material and incompressible material (see figs. 3-6) and different density parameter values. It has been seen that circumferential stresses maximum at the internal surface of the compressible material as compared to the incompressible material of spherical shell. With the introduction density parameter, circumferential as well as radial must be decreased at the internal surface of the spherical shell.

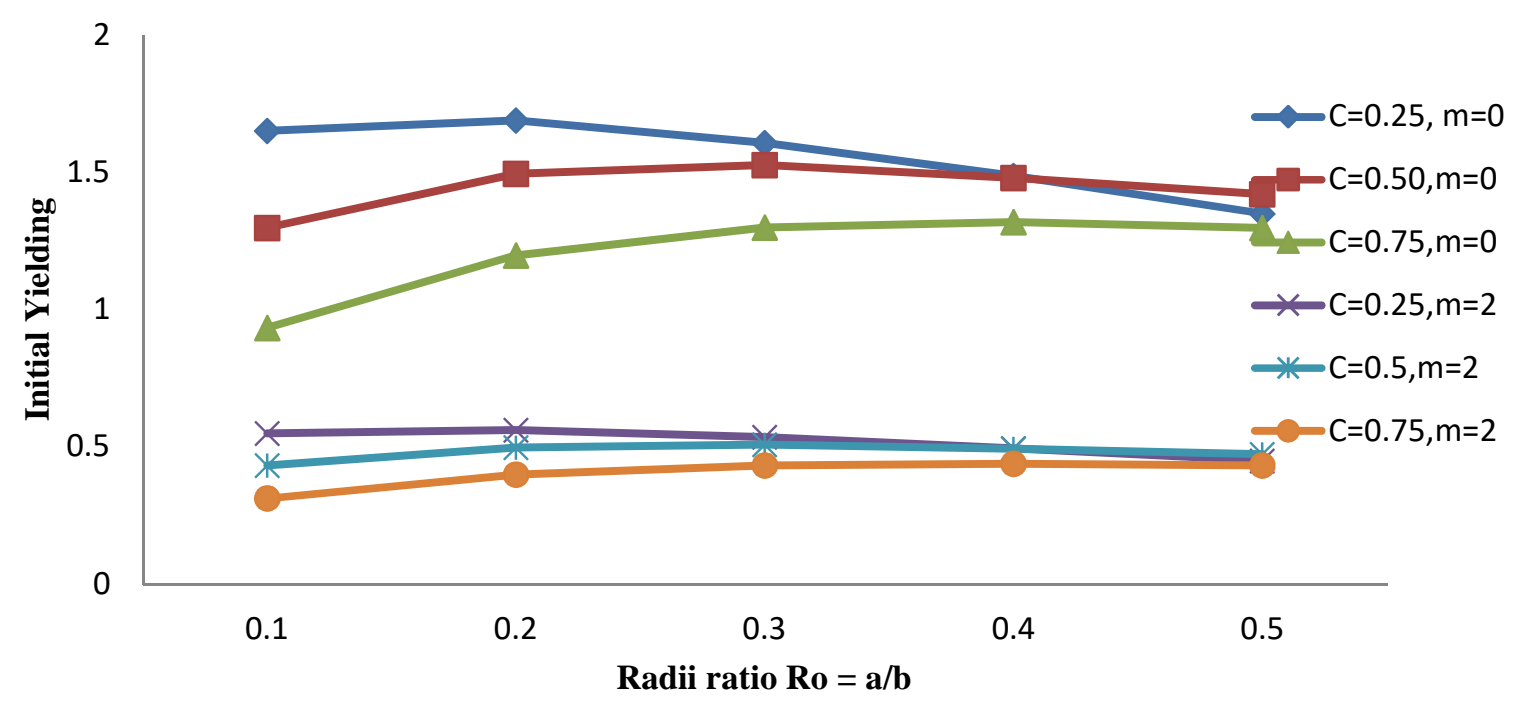

Figure2.Angular Speed required for initial yielding for various radii ratios $R_{0}=a / b$ in rotating shell with the effect of variable density parameter $(m=0,2)$. 


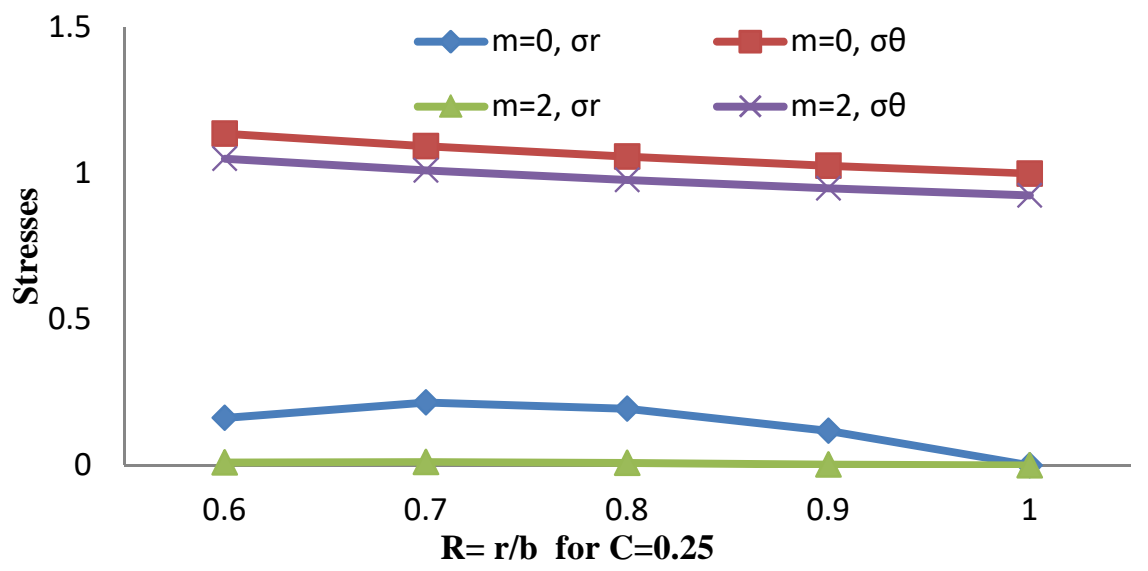

Figure3. Stresses distribution with respect to radii ratio $\mathrm{R}=\mathrm{r} / \mathrm{b}$ for $\mathrm{C}=0.25$.

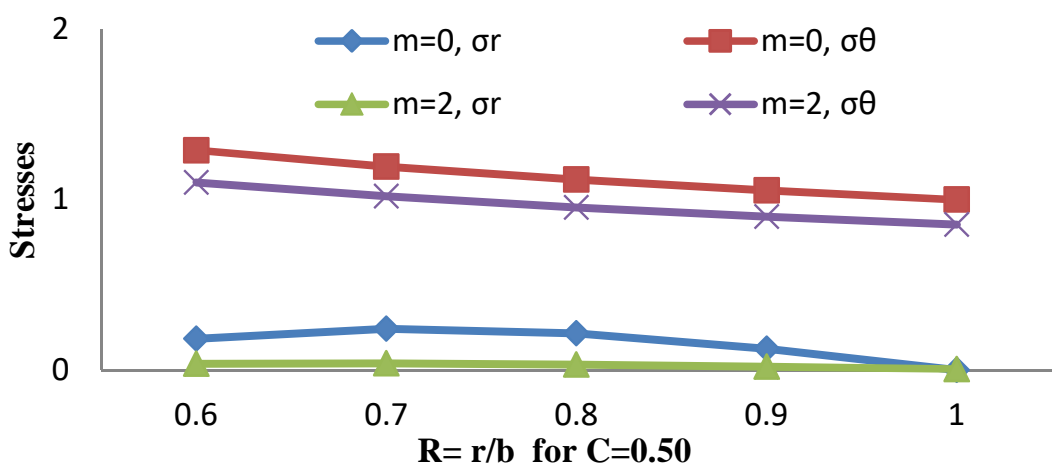

Figure4. Stress distribution with respect to radii ratio $\mathrm{R}=\mathrm{r} / \mathrm{b}$ for $\mathrm{C}=0.5$.

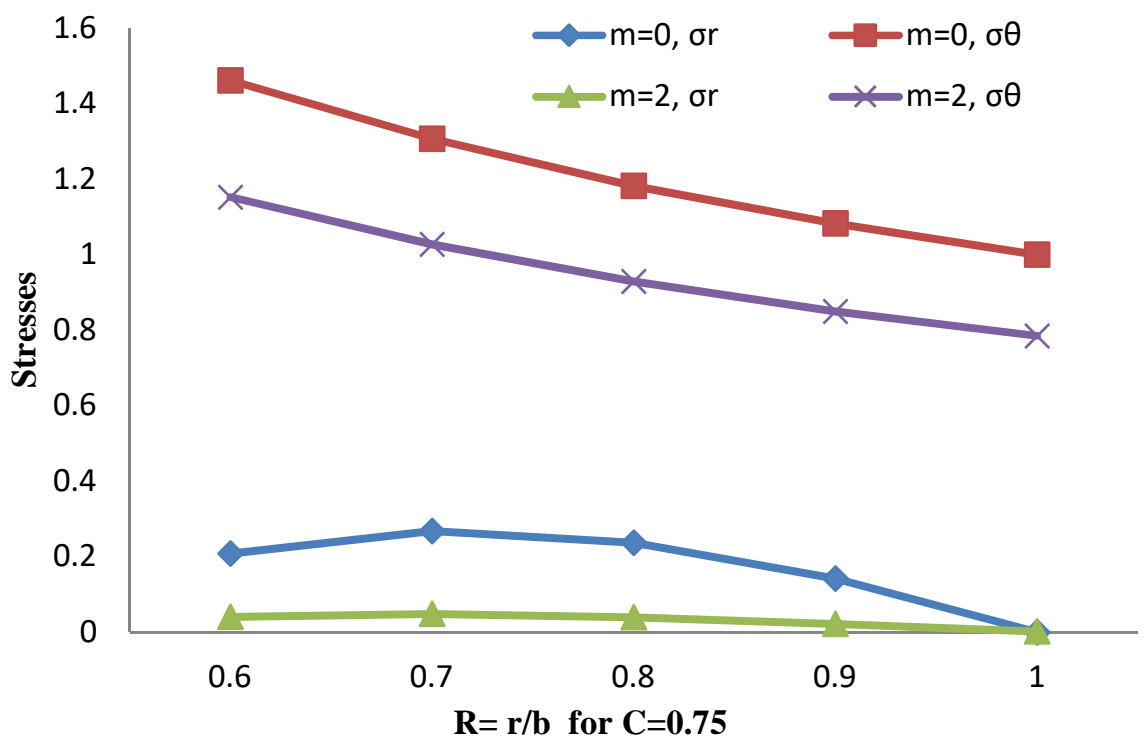

Figure5. Stress distribution with respect to radii ratio $\mathrm{R}=\mathrm{r} / \mathrm{b}$ for $\mathrm{C}=0.75$. 


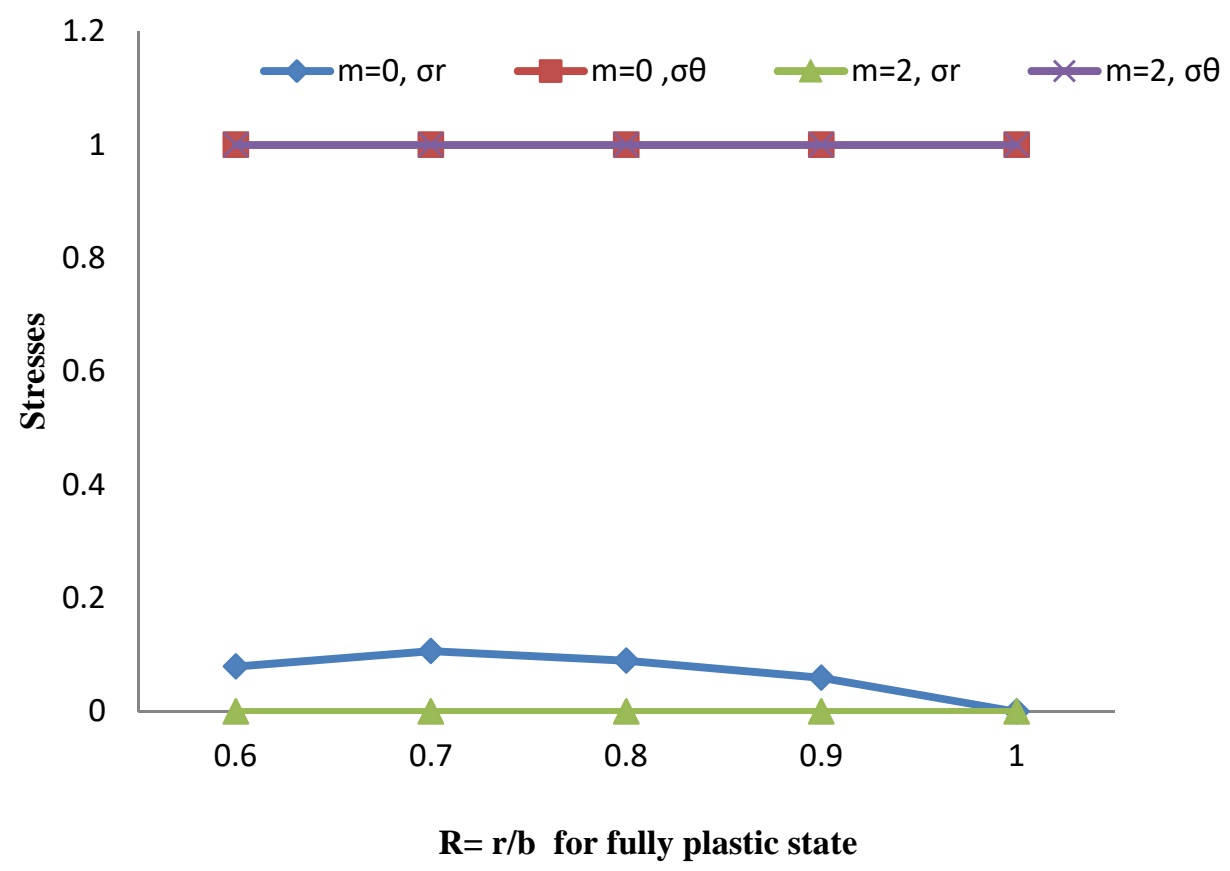

Figure6. Stress distribution with respect to radii ratio $\mathrm{R}=\mathrm{r} / \mathrm{b}$ for $\mathrm{C}=0$.

\section{Nomenclature}

$a, b \quad$ - Inner and outer radii of the spherical shell [m],

$\omega \quad$ - Angular velocity $\left[\mathrm{s}^{-1}\right]$,

$u, v, w$ - Displacement components, [m],

$\rho$ - Density of material, $\left[\mathrm{kgm}^{-3}\right]$,

C - Compressibility factor, [-],

$T_{i j}, e_{i j}-$ Stress and Strain rate tensor $\left[\mathrm{kgm}^{-1} \mathrm{~s}^{-2}\right]$,

$Y \quad$ - Yield stress, $\left[\mathrm{kgm}^{-1} \mathrm{~s}^{-2}\right]$,

$R=r / b ; R_{0}=a / b$ - Radii ratio, [-],

$\Omega^{2}=\rho_{0} \omega^{2} b^{2} / Y \quad$ - angular speed,

$\sigma_{r}$ - Radial stress component $\left(T_{r r} / Y\right),[-]$

$\sigma_{\theta} \quad$ - Circumferential stress component $\left(T_{\theta \theta} / Y\right),[-]$ 


\section{References:}

[1] Chakrabarty, J. (1987): Theory of Plasticity. McGraw-Hill Book Coy., New York.

[2] CIVAlEK, Ö., GÜRSES, M. (2009): Free vibration analysis of rotating cylindrical shells using discrete singular convolution technique. International Journal of Pressure Vessels and Piping 86 (10): 677-683.

[3] Eberlein, R., Wriggers, P. (1999): FE concepts for finite elastoplastic strains and isotropic stress response in shells: theoretical and computational analysis. Comput. Meth. Appl. Mech. Eng. 171: 243-279.

[4] Gupta, S.K.,PAThaK, S. (2000): Creep Transition in a thin rotating Disc of Variable Density. Defence Science Journal50 (2): 147-153.

[5] HulsarkaR, S. (1981): Elastic Plastic Transitions in Transversely Isotropic Shells under uniform pressure. Indian J. Pure Applied Math. 12 (4): 552-557.

[6] OdQVist, F.K.G. (1964): On theories of creep rupture. In: Reiner, M. \& Abir, D. (Eds.), IUTAM Symp. Second-Order Effects in Elasticity, Plasticity and Fluid Dynamics, Haifa, Proc. Pergamon Press: 295-313.

[7] SCHMidT, R., WEICHERT, D. (1989): A refined theory of elastic-plastic shells at moderate rotations. ZAMM 69: 11-21.

[8] SETH, B.R. (1963): Elastic Plastic Transition in Shells \& Tubes under pressure, ZAMM 43: pp. 345.

[9] SETH, B.R. (1966): Measure Concept in Mechanics. Int. J. Non-linear Mech. 1: 35-40.

[10] Shambharkar, R. (2008): Vibration analysis of thin rotating cylindrical shell. Ph.D. thesis, NIIT Rourkela.

[11] Sharma, S., SAHni, M. (2009): Elastic-Plastic Transition of Transversely Isotropic Thin Rotating Disc. Contemporary Engineering Sciences 2 (9): 433-440.

[12] Simo, J.C., RIFAI, M.S., Fox, D.D. (1990): On a stress resultant geometrically exact shell model. Part IV: Variable thickness shells with through-the-thickness stretching. Comp. Meth. Appl. Mech. Eng. 81: 91-126.

[13] Sokolnikoff, I.S. (1946): The Mathematical Theory of Elasticity. McGraw-Hill, New York.

[14] Timoshenko, S.P., GoodieR, J.N. (1970): Theory of elasticity (3rd ed.). McGraw-Hill Book Coy., New York.

[15] ThAKuR, P. (2011): Elastic-plastic transition stresses in rotating cylinder by finite deformation under steady-state temperature. Thermal Science International Scientific Journal 15(2): 537-543.

[16] ThakuR, P. (2010): Creep transition stresses in a thin rotating disc with shaft by finite deformation under steady state temperature. Thermal Science 14 (2): 425-436.

[17] Thakur, P., Singh, S.B., SAwhney, S. (2015): Elastic-Plastic Infinitesimal Deformation in a Solid Disk under Heat Effect by Using Seth Theory. Int. J. Appl. Comput. Math. 3 (2): 621-633 DOI 10.1007/s40819-015-0116-9. 
[18] Thakur, P., Kaur, J., Singh, S.B. (2016): Thermal Creep stresses and strain rates in a circular Disc with shaft having variable density. Engineering Computations 33(3): 698712 DOI 10.1108/EC-05-2015-0110.

[19] WoelKe, P.B. (2005): Computational model for elasto-plastic and damage analysis of plates and shells. LSU Doctoral Dissertations. 2945

http://digitalcommons.1su.edu/gradschool_dissertations/2945 Accessed 15 April 2016. 